Original Contribution

\title{
THE ROLE OF CD68 POSITIVE TAM IN DEVELOPMENT OF NON-SMALL CELL LUNG CANCER
}

\author{
Pl. Minkov ${ }^{1 *}$, M. Gulubova1 ${ }^{1}$ E. Obretenov² ${ }^{2}$ J. Ananiev ${ }^{1}$ \\ ${ }^{1}$ Department of General and Clinical Pathology, Medical Faculty, Trakia University, \\ Stara Zagora, Bulgaria \\ ${ }^{2}$ Department of Thoracic Surgery, Medical Faculty, Trakia University, Stara Zagora, Bulgaria
}

\begin{abstract}
Non-small cell lung cancer (NSCLC) is a leading cause of cancer related mortality. Main factors of development of NSCLC are many immune cells involved in tumor microenvironment. Infiltration with CD68 positive tumor associated macrophages (TAM) in the tumor stroma or in the tumor islets is associated with prognosis and stage of the disease for a long time. Investigating immunohistochemically 40 patients with NSCLC we discovered that $25 \%$ of patients with metastasis in lymph nodes had low infiltration with TAM in the tumor border, while $35.7 \%$ of the patients without metastasis- the infiltration was high $(\mathrm{x} 2=5.19 ; \mathrm{p}=0.023)$. We also discovered that all patients in stage I and $66.7 \%$ of the patients in stage II had low infiltration with TAM in the tumor border, while $100 \%$ of those in stage IV had high infiltration in the border ( $22=5.44 ; \mathrm{p}=0.02)$. In addition, we observed that $52.9 \%$ of the patients in T3-4 the infiltration of the tumor border with TAM was high, while only $16.7 \%$ of those in T1-2 had high infiltration $(\mathrm{x} 2=2.92 ; \mathrm{p}=0.087)$.

In investigated by our team lung cancers, clear associations were established between CD68 positive cells density in the tumor border and stage of the disease.
\end{abstract}

Keywords: NSCLC, TAM, CD68, prognosis

\section{INTRODUCTION}

Lung cancer is the most common cause for cancer related mortality. In more than $85 \%$ of the cases of lung cancer non-small cell lung cancer (NSCLC) is diagnosed (1). Many factors are involved in progression and development of the NSCLC like: genetics, factors of the environment, anti- tumor immunity, tumor microenvironment and others. The central place in the processes of tumorigenesis and anti- tumor immunity is taken by the tumor microenvironment. The escape from the immune response by the tumor is achieved in different ways, from escape of anti- tumor immunity to induction of immune tolerance, which both ease the tumor growth and progression. Main mechanisms are inhibition of the antigen presentation, inhibition of the anti- tumor immune cells, and active recruitment of immune cells by the tumor itself $(2,3)$.

\footnotetext{
*Correspondence to:PlamenMinkov, MD, Department of General and clinical pathology, Medical faculty, Trakia University Armeiska Str.11, Stara Zagora, 6000, E-mail: minkov_plamen@abv.bg
}

The tumors are infiltrated by many different immune cells. The infiltration of the tumors with specific immune cells is associated with good as well as bad prognosis, depending on the type of the cells (4). The consideration, that the defining the type, concentration and localization of the different immune cells in the tumor microenvironment could be used as predictive biomarker for progression and prognosis of the cancer is known for a long time (5).

Key component of the tumor microenvironment are the tumor associated macrophages (TAM) $(6,7)$. This group of immune cells plays an important role as immune regulator in the tumor microenvironment and is also potential target for anti- cancer therapy (8). Tumor associated macrophages demonstrate as anti- cancerous, as well pro- cancerous abilities. Which one of their abilities will be demonstrated depends on their specific polarization. There are two types of TAM, M1 type as consequence of classically activated TAM and M2 type as consequence of alternative activation of TAM (9). 
Macrophages polarized as M1 phenotype are also known as inhibitory type macrophages because of their stimulation of Th1 mediated immune response (10). Substances like interferon- $\gamma$, lipopolysaccharides, TNF- $\alpha$ and GM-CSF can induce M1 polarization and the end result is tumoricidal and bactericidal effect $(9,11,12)$.

Macrophages polarized as M2 phenotype are also known as "heeling" type macrophages, because of their role in Th2 mediated immune response $(10,11)$. The M2 type macrophages are activated by substances like IL-4, IL-10, IL-13 and prostaglandin E2 (12-14). The activated M2 macrophages induce Th2 mediated immune response and as end result processes of tissue reparation, remodeling, angiogenesis, and tumor progression are implemented $(12,13,15)$.

The dual nature of TAM in the processes of tumor progression and development is established in vitro as well as vivo studies in different types of cancer. In these studies many markers for qualification of different types of TAM were used (CD68, CD163, CD204, HLA-DR and others). It was also payed attention to the location and density of TAM in
MINKOV PL., et al. tumor border, in the tumor islets, or in both places (16-20).

The role of TAM in progression and development of NSCLC remains unclear because of some discrepancies between the results of the present studies. It is not fully determined the association between the degree of infiltration with TAM and the prognosis and stage of NSCLC.

We aimed to investigate the degree of infiltration with CD68 positive cells in a group of patients with NSCLC and to correlate the data with clinical- morphological and overall survival data.

\section{MATERIALS AND METHODS}

Biopsy materials taken from 40 patients after lung resection in Clinic of Thoracic surgery of University Hospital in Stara Zagora were investigated. The biopsies were made in the years between 2007 and 2017. The group is made up by 37 men and 3 women, the age diapason was between 24 and 77 years (mean 62.8 years). Retrospectively, clinical ad histological data was gained and are presented in Table 1.

Table.1.Themainclinicalandhistologicalparameters of thepatients $(n=40)$

\begin{tabular}{|l|l|}
\hline Parameter & Number $\mathbf{( \% )}$ \\
\hline Clinicaldata & $(n=40)$ \\
\hline $\begin{array}{l}\text { Gender } \\
\text { Male } \\
\text { Female }\end{array}$ & $37(92.5)$ \\
\hline $\begin{array}{l}\text { Age (years) } \\
\text { median } \\
\text { (range) }\end{array}$ & $3(7.5)$ \\
\hline $\begin{array}{l}\text { T stage } \\
\text { T1-2 }\end{array}$ & 62.8 \\
T3-4 & $(24-77)$ \\
\hline N stage & $6(15)$ \\
N0 & $34(85)$ \\
N1-3 & $12(30)$ \\
\hline Metastases & $28(70)$ \\
No & $33(82.5)$ \\
Yes & $7(17.5)$ \\
\hline Clinical stage & $21(52.5)$ \\
I-II & $19(47.5)$ \\
III-IV & $15(37.5)$ \\
\hline Hystological type & $25(62.5)$ \\
AC & \\
SCC & \\
\hline
\end{tabular}

The biopsy tissue is investigated by routine histochemical methods and immunohistochemically. After fixation in $10 \%$ buffered formalin, the tissue was included in paraffin and was cut in $4 \mu \mathrm{m}$ than deparaffining was made. Next step was inhibition of endogenous peroxidase for $5 \mathrm{~min}$ with blocking reagent following protocol for immune histochemical 
investigation with respective antibody. Next process was antigen revealing in buffer solution for $20 \mathrm{~min}$ in $95^{\text {' }} \mathrm{C}$. After that the cuts were washed 3 times in PBS and were incubated with primary antibody for an hour. This was followed by another 3 times washing and incubation for 20 to $40 \mathrm{~min}$ with detection system. At the end, after another wash up and incubation, twice for $5 \mathrm{~min}$ in $\mathrm{DAB}$ the probes were stained with Mayer's hematoxylin.

Immunohistochemical investigation was made with monoclonal mouse anti-human antibody CD68 (KP1, DAKO) in solution 1:100, and detection system EnVision ${ }^{\mathrm{TM}}$ FLEX+, Mouse, High pH, (Link) (K8002, DAKO).

\section{Cell counting}

The CD68 positive cells were reported in two locations: tumor border and tumor nests in so called hot spots of five fields of vision in magnification $x 320,0.74 \mathrm{~mm}^{2}$. The degree of infiltration with cells was calculated on $1 \mathrm{~mm}^{2}$.

\section{Statistical analysis}

The data of the investigations was statistically processed with SPSS for Windows Version 16 (SPSS, Inc., Chicago, IL, USA). For comparison of the frequency of the investigated parameters $\chi 2$-test was used. For tracing of the survival of the patients Kaplain- Meier analysis was used, which find the differences between curves by log- rank test. All analyses considered for reliable had level of significance $\mathrm{p}<0.05$.

\section{RESULTS}

After immunohistochemical analysis, the gained data was correlated with clinical and morphological characteristics of the patients.
MINKOV PL., et al. For this purpose the patients were divided in four groups: with low or high degree of infiltration with TAM in the tumor nests or border. Statistically significant association was found according to number of the CD68 positive cells in the tumor nests, the presence of lymph metastasis $(\mathrm{N})$ and clinical stage. A tendency according to degree of infiltration and tumor size $(\mathrm{T})$ was also established.

In $25 \%$ of the patients with lymph node metastasis, low degree of TAM infiltration in the tumor border was observed, while in $35.7 \%$ of the patients without metastasis the infiltration of the border was high grade $(x 2=5.19 ; \mathrm{p}=0.023)$. We also found that $100 \%$ of the patients diagnosed in clinical stage I and $66.7 \%$ of the patients in clinical stage II had low grade infiltration with TAM in the border, while in $100 \%$ of the patients in clinical stage IV were with high grade infiltration of the tumor border ( $\mathrm{x} 2=5.44 ; \mathrm{p}=0.02)$.

In addition, in $52.9 \%$ of the patients in T3-4 the infiltration of the tumor border with TAM was high, compared with only $16.7 \%$ of the patients in T1-2 with high infiltration of the border $(\mathrm{x} 2=2.92 ; \mathrm{p}=0.087)$.

Available data for survival was found for 31 patients but after analysis, no statistically significant correlation with degree of infiltration was established (Figures 1,2).

No others significant correlations were found in analysis of the distribution and the grade of infiltration of the investigated cells and others parameters.

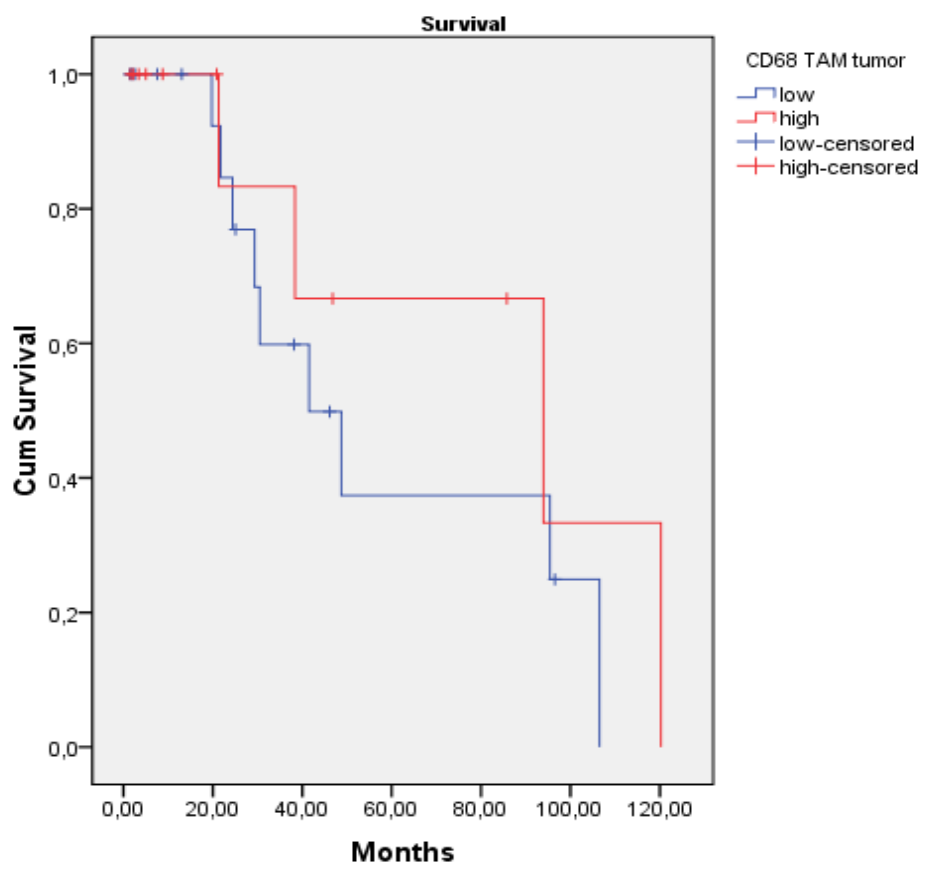

Figure 1.Associationbetweensurvivalanddegree of infiltrationwith CD68 intumornests. 


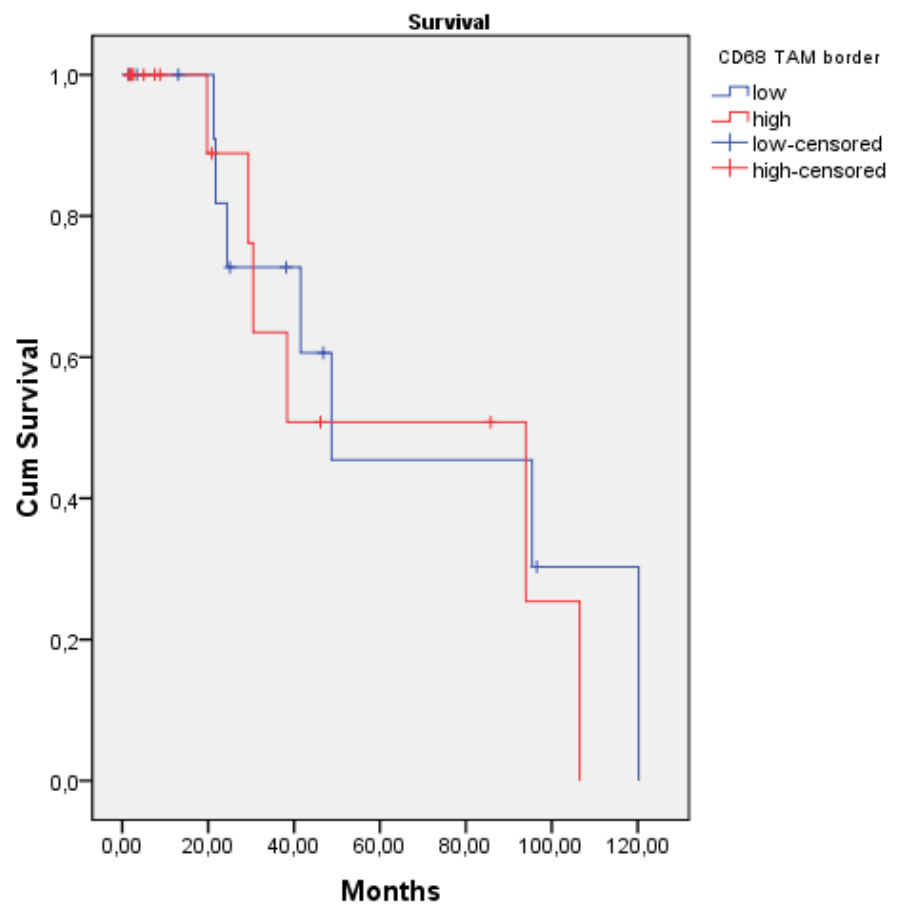

Figure 2.Associationbetweensurvivalanddegree of infiltrationwith CD68 intumorborder.

\section{DISCUSSION}

The most commonly used marker for investigation of TAM is CD68. In reviewing the available data in the literature, we found that in general there are nine studies which aimed to investigate the significance of the infiltration of NSCLC with CD68 positive cells, by paying attention of the distribution of the CD68 positive cells in the tumor border or islets $(16,19,21-27)$.

The sum of the infiltrating TAM in the tumor stroma and tumor nests fails to be associated with prognosis or severity of the disease in NSCLC, unlike in other tumors. Such association was missing after analysis of our results. Examined separately, the number of TAM infiltrating the tumor stroma and tumor nests respectively were established as informative about stage and prognosis of NSCLC. Having this in mind, in our study we divided the patients in categories according to the presence of low or high grade of infiltration with CD68 positive cells of tumor border or islets. The high grade infiltration of the tumor stroma with CD68 positive cells as well as low grade infiltration of the tumor islets indicates bad prognosis and advanced disease (19-22, 24, 26). All this data is confirmed by our results, where all patients with high degree of infiltration of the tumor border were in IV clinical stage. The presence of advanced disease could be explained by the different impact of CD68 positive cells depending on their distribution.
It is known that CD68 is a marker expressed on the surface of many different cells as monocytes, macrophages, fibroblasts, endothelial cells and even some cancer cells (28). Therefore, if CD68 is used as marker for detection of macrophages the results could be misleading.

Although, in our section was not found correlation between degree of infiltration in the tumor islets and prognosis or stage of disease, such correlation was observed in some studies. Patients with NSCLC and high grade infiltration with CD68 positive cells in tumor islets have better prognosis, and the CD68 positive cells were proven mostly as M1 type. Exactly the opposite, worse outcome is observed when the high grade of infiltration is found in the tumor stroma, where the dominant type of CD68 positive cells was M2 type. In support of this it was proven that $70 \%$ of TAM in the tumor islets is M1 type and also that TAM in tumor stroma most commonly are M2 type $(20,29)$. The difference in the distribution of M1 and M2 types of TAM is associated with prognosis and severity of disease and is totally correlating with their functions. The reverse polarization of CD68 positive TAM in tumor stroma or islets is definitive for pro- or anti- tumor capabilities that these cells realize depending on their localization.

Some studies investigated the tumor border/islet ratio of CD68 positive cells. The conclusions pointed that high border/stroma 
ratio is associated with better prognosis (19, 23, 30, 31).

In conclusion, there is no established correlation between the total count of CD68 positive cells and histological type or TNM stage in patients with NSCLC. Lack of association is found between histological type and concentration of CD68 positive cells in the tumor islets, although intensively infiltrated tumors were mostly in III- IV clinical stage. High degree of infiltration in the tumor border with CD68 positive cells is definitively associated with low grade of differentiation and presence of lymph metastasis $(16,19,23$, 24, 32).

\section{REFERENCES}

1. Siegel RL, Miller KD, Jemal A. CancerStatistics, CA Cancer $J$ Clin. 2017Jan;67(1):7-30, 2017.

2. Dunn GP, Old LJ, Schreiber RD.ThethreeEs of cancerimmunoediting. Annu Rev Immunol. 22:329-60, 2004.

3. Zitvogel L, Tesniere A, Kroemer G. Cancer despite immunosurveillance: immuno selection and immunosubversion. NatRevImmunol. Oct;6(10):715-27, 2006.

4. Talmadge JE, Donkor M, Scholar E. Inflammatory cell infiltration of tumors:Jekyll or Hyde. Cancer MetastasisRev. Dec;26(3-4):373-400, 2007.

5. Pagès F, Kirilovsky A, Mlecnik B, Asslaber M, Tosolini M, Bindea G, Lagorce C,Wind P, Marliot F, Bruneval P, Zatloukal K, Trajanoski Z, Berger A, Fridman WH,Galon J. Insitucytotoxicandmemory $\mathrm{T}$ cellspredictoutcomeinpatientswithearlystagecolorectalcancer. J ClinOncol. Dec 10;27(35):5944-51, 2009.

6. Noy R, Pollard JW. Tumorassociatedmacrophages: frommechanisms to therapy. Immunity. Jul 17;41(1):49-61, 2014.

7. Chanmee T, Ontong P, Konno K, Itano N. Tumorassociatedmacrophagesasmajorplaye rsinthetumormicroenvironment. Cancers (Basel). Aug 13;6(3):1670-90, 2014.

8. Ruffell B, Coussens LM. Macrophagesandtherapeuticresistanceincan cer. CancerCell. 2015 Apr 13;27(4):462-72.

9. Mantovani A, Locati M. Tumorassociatedmacrophagesas a paradigm ofmacrophageplasticity, diversity, andpolarization: lessonsandopenquestions. ArteriosclerThrombVascBiol.Jul;33(7):147 8-83, 2013.

10.Mills CD, Ley K. M1 and M2 macrophages: thechickenandtheegg of immunity. JInnateImmun. 6(6):716-26, 2014.
11.Mills CD. M1 and M2 Macrophages: Oracles of Health andDisease. CritRevImmunol. 32(6):463-88, 2012.

12.Biswas SK, Allavena P, Mantovani A. Tumor-associatedmacrophages:

functionaldiversity, clinicalsignificance, andopenquestions. SeminImmunopathol. Sep;35(5):585-600, 2013.

13. Sica A, Larghi P, Mancino A, Rubino L, Porta C, Totaro MG, Rimoldi M, BiswasSK, Allavena P, Mantovani A. Macrophage polarization in tumour progression. SeminCancerBiol. Oct;18(5):349-55, 2008.

14.Liu L, Ge D, Ma L, Mei J, Liu S, Zhang Q, Ren F, Liao H, Pu Q, Wang T, You Z. Interleukin-17 and prostaglandin $\mathrm{E} 2$ are involved in formation of an M2macrophage-dominan tmicroenvironment in lungcancer. $J$ ThoracOncol. Jul;7(7):1091-100, 2012.

15. Guo C, Buranych A, Sarkar D, Fisher PB, Wang XY. Therole of tumorassociatedmacrophagesintumorvascularizati on. VascCell. Dec 6;5(1):20, 2013.

16.Pei BX, Sun BS, Zhang ZF, Wang AL, Ren $\mathrm{P}$ Interstitialtumor-associatedmacrophagescombinedwithtumor-derivedcolonystimulating factor-1 andinterleukin-6, a novelprognosticbiomarkerinnon-smallcelllungcancer. JThoracCardiovascSurg. Oct;148(4):1208-1216.e2, 2014.

17. Carus A, Ladekarl M, Hager H, Pilegaard $\mathrm{H}$, Nielsen PS, Donskov F.Tumorassociatedneutrophilsandmacrophagesinnon -smallcelllungcancer: noimmediateimpactonpatientoutcome. LungCancer. Jul;81(1):130-7, 2013.

18. Hirayama $\mathrm{S}$, Ishii $\mathrm{G}$, Nagai $\mathrm{K}$, Ono $\mathrm{S}$, Kojima M, Yamauchi C, Aokage K, HishidaT, Yoshida J, Suzuki K, Ochiai A. Prognosticimpact of CD204-positive macrophagesinlungsquamouscellcarcinoma :possiblecontribution of Cd204positivemacrophages to the tumorpromotingmicroenvironment.

ThoracOncol. Dec;7(12):1790-7, 2012.

19.Dai F, Liu L, Che G, Yu N, Pu Q, Zhang S, Ma J, Ma L, You Z. Thenumberandmicrolocalization of tumorassociatedimmunecellsareassociatedwithpat ient'ssurvivaltimeinnon-smallcell-

lungcancer. BMC Cancer. May 20;10:220, 2010.

20.Ohri CM, Shikotra A, Green RH, Waller DA, Bradding P. Macrophageswithin NSCLCtumourisletsarepredominantly of a cytotoxic M1 phenotypeassociatedwithextendedsurvival. EurRespir J. Jan;33(1):118-26, 2009. 
21.Zhang B, Yao G, Zhang Y, Gao J, Yang B, Rao Z, Gao J. M2-polarizedtumorassociatedmacrophagesareassociatedwithpo orprognosesresultingfromacceleratedlymph angiogenesisinlungadenocarcinoma. Clinics (SaoPaulo. 66(11):1879-86, 2011.

22.daCostaSouza P, Parra ER, Atanazio MJ, daSilva OB, Noleto GS, Ab'Saber AM, deMoraisFernezlian $\mathrm{S}$, Takagaki $\mathrm{T}$, Capelozzi VL. Differentmorphology, stageandtreatmentaffectimmunecellinfiltrati onandlong-termoutcomeinpatientswithnonsmall-celllungcarcinoma.Histopathology. Oct;61(4):587-96, 2012.

23.Feng $\mathrm{PH}, \mathrm{Yu} \mathrm{CT}, \mathrm{Wu} \mathrm{CY}$, Lee MJ, Lee WH, Wang LS, Lin SM, Fu JF, Lee KY, Yen TH.Tumor-associatedmacrophagesinstage IIIA $\mathrm{pN} 2$ nonsmallcelllungcancerafterneoadjuvantchemot herapyandsurgery. Am J TranslRes. Oct 11;6(5):593-603.eCollection 2014, 2014.

24.Kim DW, Min HS, Lee KH, Kim YJ, Oh DY, Jeon YK, Lee SH, Im SA, Chung DH, KimYT, Kim TY, Bang YJ, Sung SW, Kim JH, Heo DS. High tumour islet macrophage infiltration correlates with improved patient survival but not with EGFR mutations, gene copy number or protein expression in resected non-small cell lung cancer. $\mathrm{Br} J$ Cancer. Mar 25;98(6):1118-24, 2008.

25.Chen JJ, Yao PL, Yuan A, Hong TM, Shun CT, Kuo ML, Lee YC, Yang PC.Upregulation of tumor interleukin-8 expression by infiltrating macrophages: its correlation with tumor angiogenesis and patient survival in non-small cell lung cancer. ClinCancerRes. Feb;9(2):729-37, 2003.

26.Takanami I, Takeuchi K, Kodaira S. Tumor-associatedmacrophageinfiltration-
MINKOV PL., et al.

inpulmonaryadenocarcinoma:

associationwithangiogenesisandpoorprogno sis.Oncology. 57(2):138-42, 1999.

27.Eerola AK, Soini Y, Pääkkö P. Tumourinfiltratinglymphocytesinrelation totumourangiogenesis, apoptosisandprognosisinpatientswithlargece lllungcarcinoma. LungCancer. Nov; 26 (2): 73-83, 1999.

28.Gottfried E, Kunz-Schughart LA, Weber A, Rehli M, Peuker A, Müller A,Kastenberger M, Brockhoff G, Andreesen R, Kreutz M. Expression of CD68 innonmyeloidcelltypes. Scand J Immunol. May; 67(5):453-63, 2008.

29.Ma J, Liu L, Che G, Yu N, Dai F, You Z. The M1 form of tumorassociatedmacrophagesinnonsmallcelllungcancerispositivelyassociated withsurvivaltim e. BMC Cancer. Mar 25;10:112, 2010.

30. Kawai O, Ishii G, Kubota K, Murata Y, Naito $Y$, Mizuno $T$, Aokage $K$, Saijo N,Nishiwaki Y, Gemma A, Kudoh S, Ochiai A. Predominantinfiltration of macrophagesand $\mathrm{CD} 8(+) \quad \mathrm{T}$ Cellsincancernestsis a significantpredictor of survivalinstage IV nonsmallcelllungcancer. Cancer. Sep15;113(6):1387-95, 2008.

31. Cota GF, deSousa MR, Fereguetti TO, Rabello A. Efficacy of antileishmaniatherapyinvisceralleishmaniasisa mong HIV infectedpatients: a systematicreviewwithindirectcomparison. PLoSNeglTropDis. May 2;7(5):e2195, 2013

32. Welsh TJ, Green RH, Richardson D, Waller DA, O'Byrne KJ, Bradding P.Macrophageandmast-cellinvasion of tumorcellisletsconfers a markedsurvivaladvantageinnon-small-celllungcancer. JClin Oncol. Dec10;23(35):8959-67, 2005. 